\title{
Self-reported Motorcycle Riding Behavior in Southeast of Iran
}

\author{
Fatemeh Setoodehzadeh (iD ${ }^{1}$, Alireza Ansari-Moghaddam (iD ${ }^{1}$, Hassan Okati-Aliabad (iD) ${ }^{1}$, Mohammad \\ Khammarnia (iD) ${ }^{1, *}$ and Mahdi Mohammadi (iD) 1 \\ ${ }^{1}$ Health Promotion Research Center, Zahedan University of Medical Sciences, Zahedan, Iran \\ "Corresponding author: Health Faculty, Zahedan University of Medical Sciences, Zahedan, Iran. Email: m_khammar1985@yahoo.com
}

Received 2021 May 16; Revised 2021 August 20; Accepted 2021 August 31.

\begin{abstract}
Background: Motorcyclists are among the greatest vulnerable individuals of road accident victims. Their behavior has a significant correlation with increased injury and mortality rate. Determining the risky and unsafe behaviors of motorcycle drivers is necessary for preventing riders and other citizen from potential accident risks.

Objectives: The aim of this study was to determine the risky driving behaviors of motorcyclists in Iran.

Methods: A cross-sectional study was done in 2019 in Sistan and Baluchestan Province as the second widest province of Iran. Using randomized sampling method, we included 613 motorcyclists from the province. To collect data, the Persian version of Motorcycle Riding Behavior Questionnaire (MRBQ), as a standard questionnaire, was used. For data analysis, descriptive and analytical statistics such as one-way analysis of variance (ANOVA), $t$-test, and linear regression were used by SPSS software version 21.

Results: The age range of $57 \%$ of the motor riders was 15 - 30 years, and $50 \%$ of them did not use any safety equipment. About $58 \%$ of the subjects had started motorcycle riding under 18 years old, and $73 \%$ of them did not have a motorcycle riding license. Moreover, more than $50 \%$ of motorcyclists used mobile phones while driving. The mean score of driving behavior (106 \pm 22$)$ was desirable. Based on multivariate analysis, job, average amount of riding, lacking a riding license, type of motor, alert from police, non-fasting helmet band, exceeding speed limits, fatigue, and hand-free riding were the main predictors of risky riding score $(\mathrm{P}<0.05)$.

Conclusions: According to our results, the riding behavior of motorcyclists was desirable; however, many people used motorcycles without a license and safety equipment, which increases high-risk behaviors. Considering the potential dangers of motor riders, it seems necessary to hold training courses to obtain motorcycle certification and how to use safety equipment.
\end{abstract}

Keywords: Motorcycles, Health Risk Behaviors, Head Protective Devices, Iran

\section{Background}

It is widely recognized that road safety is a public health challenge. According to the World Health Organization (WHO), road traffic accidents are amongst eight leading causes of death worldwide (1). Additionally, nearly 3400 people die every day on roads (one death on road every $24 \mathrm{~s}$ ) in the world (2). Motorcycle riders' behaviors continue to be a challenge in both developing and Organization for Economic Cooperation and Development (OECD) member countries (3). Their behaviors play a key role in increasing the mortality rate due to traffic crashes (4). According to international reports, the probability of motorcycle accident is 9.3 times more than car accident (5). According to a report, about $40 \%$ of motorcycle riders had been involved in accidents during a year in Asia (6). It has been shown that in eastern Mediterranean region countries, including Iran, motorcycle injuries are a major public health problem (7). As noted in the reports of the WHO, the rate of road accidents in Iran exceeds the global average (about 13 times more than the global average). This report places Iran among the countries with the highest road traffic death rate $(8,9)$. In this regard, many people die or get injured each year as a result of these accidents (10).

Motorcycle is inherently unsafe and is increasingly used by the youth (11). It is a popular mode of transportation in many developing countries, including Iran (12). The huge number of motorcycles on road may cause the high rates of motorcycle accidents $(1,13)$. It is estimated that about $30 \%$ of the motor vehicles are motorcycles (14). Iran, along with other countries that have large numbers of motorcycles is facing great motorcyclist fatalities. In Iran, more than $51 \%$ of transport accidents leading to death or hospitalization occur among motorcycle riders (15). According to a national survey in Iran between 2011 - 2017, about $23 \%$ of fatal traffic injuries were related to motorcycle users (16).

Investigations have shown that most traffic crashes are 
the result of incorrect human behaviors (17). In this regard, Hussain (18) found that a one-unit increase in distracted violations increased the probability of being involved in road traffic accident by $54 \%$. It is believed that, given the high vulnerability of motorbike riders $(19,20)$, they have priority for examination and intervention $(4,21)$. Besides, studies on traffic accidents among underage users of motorcycles are seldom in the literature (22).

As mentioned above, Iran is one of the countries with a very high number of motorcycles (about 30\% of all vehicles); therefore, understanding motorcycle riders' risky behaviors is essential for developing effective interventions (23). Besides, motorcycle riders are among the most vulnerable road users (24). Hence, recognizing the risky actions of motorbike riders is important to prevent, sustain, and develop the health of this group and other society members.

\section{Objectives}

According to a previous study, the rate of road traffic injury and mortality is high in Sistan and Baluchestan Province (25). Hence, the aim of this study was to determine the riding patterns and risky riding behaviors of motorcycle riders in Sistan and Baluchestan as the second widest province of Iran and investigating some of its predictors. The findings of this study would increase knowledge of motorcycle safety and can be used by the policymakers to enhance road safety.

\section{Methods}

A cross-sectional study was carried out in Sistan and Baluchestan, the second widest province of Iran, in 2019. The province, as a developing region with about three million people, is located in the southeast of Iran (26). The study population consisted of all motorcycle riders living in the province in 2019.

According to the objectives of the study, the average score of motorcycle riding behavior was extracted from the previous studies. The sample size was estimated to be 600 individuals through considering the first type error of 0.05 , power of $80 \%$, and relative error of 0.05 . Hence, we used multi-stage randomized as the sampling method in the province. In this regard, four densely populated cities of the province, including Zahedan, Zabol, Chabahar, and Iranshahr, were considered as clusters (Figure 1). Therefore, in proportion to the population, the samples were randomly selected from the four regions.

Inclusion criteria were living in Sistan and Baluchestan province, the use of motorcycles more than once, and ability to communicate and respond to questions. Also, having mental disorders and reluctance to participate in the study were regarded as the exclusion criteria.

\subsection{Study Instrument}

For data collection, we used the Persian version of Motorcycle Riding Behavior Questionnaire (MRBQ). The MRBQ was advanced to examine behavioral factors influencing motorbikes' crash risk, including faults and violations along with the use of motorcycle safety equipment and tools via self-report (27). The validity and reliability of the questionnaire have been approved and reported in some previous studies in Iran $(28,29)$. The questionnaire included two sections: the first part comprises demographic information, history of riding a motorcycle, use of helmet, maneuvering on a motorcycle, and history of an accident; and the second part covers the motorcycle riding behavior. This section consists of 48 questions on six dimensions, including speed violations (11 items), traffic errors (12 items), safety violations (7 items), traffic violations (5 items), stunts (7 items), and control errors (6 items), with a 5-point Likert (never, rarely, sometimes, often, and most of the times) for scoring (28). Since the questions are negative, a "never" answer gives score 1 , and the "most of the times" answer gives score 5 . Therefore, the total driving behavior score in the worst case is 240 . Achieving higher scores in this questionnaire indicates high-risk behaviors among individuals. According to the range of the questions in this study, scores between 48 - 112 were calculated as an appropriate motorcycle riding behavior, scores between 112 - 176 as a moderate behavior, and scores between 176 - 240 as inappropriate riding behavior.

\subsection{Data Collection}

The data were gathered from motorcyclists in four cities of Sistan and Baluchestan province. The participants were selected randomly in traffic places by the researchers. Considering the crowd, the interview with motorcycle riders to fill the questionnaire was done in streets and a quiet place. In this regard, the study objectives were explained to participants, and an informed consent form was obtained from all participants.

For data analysis, we used SPSS software version 21 . Also, we used descriptive statistics and analytical statics such as one-way analysis of variance (ANOVA), $t$-test, and linear regression.

The study was approved by the Ethical Board of Zahedan University of Medical Sciences.

\section{Results}

As Table 1 shows, a total of 613 motor rider participated in the study, of whom about $57 \%$ were in the age range of 


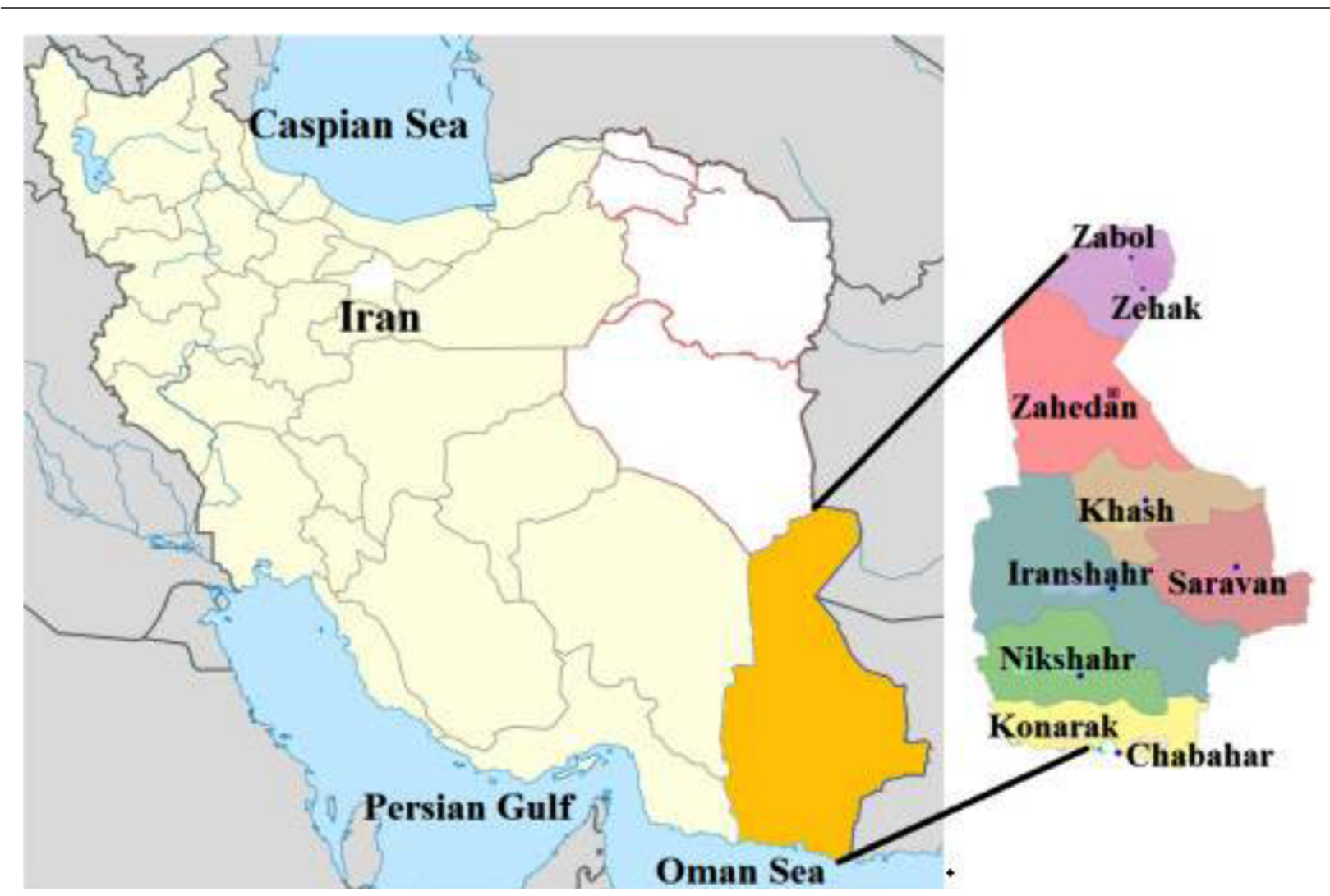

Figure 1. Map of Sistan and Baluchestan Province and its Regions

15 - 30 years old. Also, 68\% of the participants were workers with a non-governmental job. In addition, the education level of about $66 \%$ of the motorcycle riders was under diploma, and most of them were married. About $58 \%$ of the subjects had started motorcycle riding under 18 years old. About $58 \%$ of the participants used motorcycles daily. About $73 \%$ of the riders did not have a motorcycle riding license. As shown in Table 1 test, $58 \%$ of the participants had started motorcycle riding in the age range of 10 - 18 years. Also, $58 \%$ of the subjects used motorcycles to travel to their workplace, and $25 \%$ of them never used a helmet.

There was a significant relationship between riding behavior and age group $(\mathrm{P}=0.001)$. Also, unemployed riders had the highest score of behavior; hence, there was a significant relationship between riding behavior and employment status $(\mathrm{P}=0.001)$. As shown in Table 1 , there was a significant relationship between riding behavior and place of living, so that participants who lived in Iranshar had the highest score $(\mathrm{P}<0.001)$. Motorcyclists with lower monthly incomes had the highest score and the relationship was significant $(\mathrm{P}=0.025)$. Also, motorcyclists with daily riding pattern had the highest score, and the relation- ship was significant $(\mathrm{P}=0.001)$. The individuals who did not have a motorcycle riding license had the highest riding behavior score, and the relationship was significant ( $P$ $=0.001$ ). Also, the riders who received alerts from the police and had a crash experience had the highest score, and the relationship was significant $(P=0.001$. The motorcyclists that used helmet had the lowest score, and the relationship was significant $(\mathrm{P}=0.02)$. According to the results, motorcyclists that used mobile phones while riding rode in a hands-free way, talked with pillion passengers while riding, and exceeded the speed limit had the highest score $(\mathrm{P}=0.001)$ (Table 1$)$.

According to Table 2, the mean score of riding behavior in speed violation dimension was 25.3, traffic error dimension was 24.25 , safety violation dimension was 13.1 , traffic violation dimension was 11.65, stunt dimension was 11.91, and control error dimension was 13.26. Also, the total riding behavior score was $106 \pm 22$, which was desirable.

As Table 3 shows, the motorcyclists' riding behavior was considered as a dependent variable. According to the results of this table and based on linear regression analysis, the following factors increased high-risk riding behav- 


\begin{tabular}{|c|c|c|c|}
\hline Dimension & Min & Max & Mean \pm SD \\
\hline Speed violation & 11 & 55 & $25.3 \pm 7.76$ \\
\hline Traffic error & 12 & 48 & $24.25 \pm 6.25$ \\
\hline Safety violation & 7 & 33 & $13.1 \pm 3.77$ \\
\hline Traffic violation & 5 & 24 & $11.65 \pm 3.25$ \\
\hline Stunt & 7 & 31 & $15.91 \pm 4.09$ \\
\hline Control error & 6 & 27 & $13.28 \pm 4.07$ \\
\hline Behavior & 57 & 201 & $106 \pm 22.99$ \\
\hline
\end{tabular}

iors among motorcyclists: unemployment, use of powerful motorcycles, daily use of motorcycles, alert from police, not having a motorcycle riding license, riding in states of fatigue, fasting helmet band, hands-free riding, and exceeding speed limits.

\section{Discussion}

Understanding motorcycle riders' risky behaviors is essential to developing effective interventions and preventing accidents (23). This study aimed to determine the riding patterns and risky behaviors of motorbike riders in Sistan and Baluchestan, Iran. Based on the results, the mean riding behavior score by the motorcyclists was desirable. Proper riding behavior prevents many accidents, especially in developing countries. In this regard, Stephens showed that riders reported relatively safe behaviors in Australia (30).

The results of the study showed that the mean score of MRBQ was higher among the riders with a history of crash and accident in the past year, which was consistent with another study by Heydari et al. (28) reporting that about $22 \%$ of the riders had an accident experience. Moreover, a study showed that about $15 \%$ of participants had an accident while riding a motorcycle (22). Riders with a history of accident should pay more attention to their riding skills. It is also recommended that the police and family continuously monitor the behavior of this group of people.

According to the results, riding at a high speed inside the city was a predictor of risky behavior. In this regard, Hassanzadeh found that exceeding the permissible speed could result in accident (4). The report of a national survey in Indonesia showed that speeding was significantly associated with motorcycle accidents (6). Riding at high speeds certainly reduces the rider's ability in emergencies, and thus increases the likelihood of an accident. Therefore, riding at a legal and safe speed is the only way to reduce accidents.
Based on our results, about $73 \%$ of the motorcycle riders did not have a motorcycle riding license. Similarly, some other studies showed that not having a motorcycle riding license is a main predictor of risky behavior among riders $(4,31)$. In this regard, Umniyatun reported that $91.3 \%$ of motorcycle riders in Indonesia did not have a riding license (6). It is suggested that appropriate mechanisms for certification of such motorcyclists be implemented by the relevant organizations.

Our results also showed that receiving alert from police in the previous year was a main prognosticator of risky behavior among motorcycle riders. Following this, about one-third of the participants had received alert one year before the study. In this regard, Rathinam (22) found that aggressive behavior and previous encounter with the police are two strong predictors of accidents.

Moreover, using mobile phones and riding in a handsfree way are other predictors of risky behavior among motorcyclists. Our results showed that more than $50 \%$ of motorcyclists used mobile phones while driving. Truong found that calling while riding a motorcycle had the highest prevalence (74\%). He also demonstrated that perceived collision risks reduced the probability of risky riding behaviors, including calling, texting, speeding, and running red lights (23). Accordingly, the police need to enforce the necessary regulations for not using mobile phones while riding motorcyclists. The use of educational programs in schools, universities, and communication media is also recommended.

According to the findings, fasting helmet band and not using helmets by passengers are other predictors of risky behavior, which could result in accident and trauma for riders. In this regard, Hassanzade approved that taking another person without helmet by motorcycle is a risky behavior among motorcycle riders (4). Boonchooduang found that the prevalence of unprotected riding and other risk behaviors in Thai adolescents was high, and about 36\% of them did not use a helmet (32). Moreover, Haqverdi found that only $47 \%$ of the motorbike riders used a hel- 


\begin{tabular}{|c|c|c|c|c|c|c|}
\hline Variable & B & Std. Error & Beta & $t$ & P-Value & CI \\
\hline Employment status & -3.315 & 1.040 & -0.122 & -2.629 & 0.002 & $-5.378-1.271$ \\
\hline Average amount of riding & 2.761 & 0.708 & 0.162 & 3.900 & 0.001 & $1.370-4.152$ \\
\hline Type of motor & 4.023 & 0.880 & 0.174 & 4.572 & 0.001 & $2.295-5.751$ \\
\hline Alert from police & -4.408 & 1.847 & -0.090 & -2.387 & 0.017 & $-8.036-0.779$ \\
\hline Fasting helmet band & 1.582 & 0.581 & 0.105 & 2.820 & 0.005 & $0.480-2.684$ \\
\hline Exceeded speed & -3.329 & 0.738 & -0.171 & -4.511 & 0.001 & $-4.778-1.879$ \\
\hline Riding in fatigue & -1.601 & 0.752 & -0.083 & -2.128 & 0.034 & $-3.079-1.122$ \\
\hline Hands-free riding & -3.715 & 0.662 & -209 & -5.610 & 0.001 & $-5.016-2.414$ \\
\hline
\end{tabular}

met; however, a considerable proportion of these individuals did not wear their helmet appropriately (33). Since head trauma is the major cause of death (59.0\%) among motorbike riders (16), using a helmet is necessary, and strict and smart rules should be applied for this issue.

According to the results, unemployed and daily wage workers were other prognosticators of a risky riding behavior. In this study, the monthly income of majority of motorcyclists was less than 100 USD. The findings of a study showed that more than $70 \%$ of motorcyclists were either unemployed or had low income as compared to average annual income (18). In addition, a study showed that motorcyclists who were students or those who worked more than 50 hours per week were more likely to engage in risky driving behaviors (34). Barzegar et al. (16) reported that the highest rate of mortality in Iran belonged to self-employed people (38.4\%) followed by workers (21.8\%). According to these results, it is suggested that more training be provided to these groups on the risks of accidents and proper use of motorcycles.

According to the results, about $50 \%$ of the riders did not use any safety equipment. Hassanzadeh found that using safety equipment is a predictive factor of trauma among motorcyclists (4).

In this study, the education level of about $67 \%$ of riders was under diploma; the relationship between education level and riding score was to some extent significant $(\mathrm{P}=0.058)$. Several other studies reported that people with lower education had more high-risk behaviors $(4,28$, 31). Barzegar et al. reported that most fatalities (77.5\%) occurred in motorcycle rider with low education (16). The results of a study in Pakistan declared that about $67 \%$ of riders had undergraduate education (18). Boonchooduang reported that attending secondary school and those with undergraduate degree were in the group of people with an unprotected riding pattern (32).

According to the results, the mean point of MRBQ was higher among motorcyclists who used more powerful motorcycle. Heydari's report confirmed this finding. In this regard, Pervez reported that heavy vehicle is positively associated with fatalities. He found that motorcycles with heavy engines have greater performance that gives less reaction time to the riders in the event of a collision; thus, it increases the likelihood of fatality or injuries (35).

According to our results, daily use of motorcycles increased the likelihood of high-risk behaviors, which was consistent with the study by Heydari. Also, Pitaktong reported that the need for daily motorcycle usage increased the likelihood of unprotected riding (36). Accordingly, it is recommended that people avoid using motorcycles for short distances.

\subsection{Strengthens and Limitations of the Study}

The strength of this study is that it has been conducted for the first time in the Sistan and Baluchestan Province, and its results can help decision-making and policy-making in different institutions of the province. However, this cross-sectional study was carried out in a single province of Iran; therefore, generalizing its results to other populations should be done cautiously. Also, collecting data from the target community took a long time.

\subsection{Conclusions}

Our results showed that the motorcyclists' riding behavior was desirable in the southeast of Iran. However, many people used motorcycles without a license and safety equipment, which increases high-risk behaviors. Due to the high costs of motorcyclist accidents, including mortality from these accidents, accident-causing risky behaviors should be prevented. Considering the potential dangers of motorcycle riders, it seems necessary to hold training courses to obtain motorcycle certification and how to use safety equipment. It is suggested that more studies be 
conducted in the future on hospital costs of motorcyclists who had an accident and evaluate the effect of training on motorcyclists. The findings of this study would increase knowledge of motorcycle safety and can be used by the policymakers to enhance road safety in Iran.

\section{Footnotes}

Authors' Contribution: All authors equally contributed to all sections of the manuscript preparation.

Conflict of Interests: The authors declared no conflicting interests.

Ethical Approval: This study was approved by the Ethic Committee of Zahedan University of Medical Sciences (IR.ZAUMS.REC.1397.089).

Funding/Support: Zahedan University of Medical Sciences funded this study (grant no. 8634).

Informed Consent: An informed consent form was obtained from all participants.

\section{References}

1. Yuen CW, Karim MR, Saifizul A. Investigation on motorcyclist riding behaviour at curve entry using instrumented motorcycle. Sci World J. 2014;2014:968946. doi: 10.1155/2014/968946. [PubMed: 24523660]. [PubMed Central: PMC3913517].

2. Shrivastava S, Shrivastava P. Global reduction in the incidence of deaths associated with road traffic injuries: World Health Organization.MAMCJMed Sci.2019;5(3). doi: 10.4103/mamcjms.mamcjms_62_19.

3. Radin Umar RS, Mackay GM, Hills BL. Preliminary analysis of motorcycle accidents: Short-term impacts of the running headlights campaign and regulation in Malaysia.J Traffic Med.1995;23(1):17-28.

4. Hassanzadeh K, Salarilak S, Sadeghi-Bazargani H, Golestani M. Motorcyclist risky riding behaviors and its predictors in an Iranian population.J Inj Violence Res. 2020;12(2). doi: 10.5249/jivr.v12i2.936.

5. Horswill MS, Helman S. A behavioral comparison between motorcyclists and a matched group of non-motorcycling car drivers: Factors influencing accident risk. Accid Anal Prev. 2003;35(4):589-97. doi: 10.1016/s0001-4575(02)00039-8.

6. Umniyatun Y, Nurmansyah MI, Farradika Y, Purnama TB, Hidayat DN. Motorcycle risky behaviours and road accidents among adolescents in Jakarta metropolitan area, Indonesia. Int J Inj Contr Saf Promot. 2021;28(3):339-46. doi: 10.1080/17457300.2021.1928229. [PubMed: 34058942].

7. Abedi L, Sadeghi-Bazargani H. Epidemiological patterns and risk factors of motorcycle injuries in Iran and Eastern Mediterranean Region countries: A systematic review. Int J Inj Contr Saf Promot. 2017;24(2):263-70. doi: 10.1080/17457300.2015.1080729. [PubMed: 26394286].

8. Yonesian M, Moradi A. Knowledge, attitude and practice of drivers on regulation of traffic in Tehran.J Sch Public Health Instit Public Health Res. 2005;2.

9. Tefft BC. Impact speed and a pedestrian's risk of severe injury or death. Accid Anal Prev. 2013;50:871-8. doi: 10.1016/j.aap.2012.07.022. [PubMed: 22935347].

10. Jouybari L, Sanagoo A, Gadimi A, Tahanian M, Sabzi Z. [The knowledge and attitudes of driving license trainee of first aids for the victims of road accidents].J Gorgan Bouyeh Faculty Nurse Midwifery. 2010;7(1):41-7. Persian.
11. Patel PB, Staley CA, Runner R, Mehta S, Schenker ML. Unhelmeted motorcycle riders have increased injury burden: A need to revisit universal helmet laws. J Surg Res. 2019;242:177-82. doi: 10.1016/j.jss.2019.03.023. [PubMed: 31078903].

12. Ghafori S, khavanin A, Assilean H, Solimanian A. Assessing the application of the flexible joint in the exhaust pipe and braided wire damper in muffler on the sound emitted by the CG125 motorcycle exhaust. Health Scope. 2016;5(3). doi: 10.17795/jhealthscope-24154.

13. Mohammadi M, Imani M, Tajari F, Akbari F, Rashedi F, Ghasemi A, et al. Human and vehicle factors in motor vehicle crashes and severity of related injuries in South East Iran. Health Scope. 1970;1(2):61-5. doi: $10.5812 / j h s .6838$.

14. Saadat S, Rahmani K, Moradi A, Zaini SA, Darabi F. Spatial analysis of driving accidents leading to deaths related to motorcyclists in Tehran. Chin J Traumatol. 2019;22(3):148-54. doi: 10.1016/j.cjtee.2018.12.006. [PubMed: 31056469]. [PubMed Central: PMC6543188].

15. Karkhaneh M, Naghavi M, Rowe BH, Hagel BE, Jafari N, Saunders LD. Epidemiology of bicycle injuries in 13 health divisions, Islamic Republic of Iran 2003. Accid Anal Prev. 2008;40(1):192-9. doi: 10.1016/j.aap.2007.05.006. [PubMed: 18215548].

16. Barzegar A, Ghadipasha M, Forouzesh M, Valiyari S, Khademi A. Epidemiologic study of traffic crash mortality among motorcycle users in Iran (2011-2017). Chin J Traumatol. 2020;23(4):219-23. doi: 10.1016/j.cjtee.2020.05.008. [PubMed: 32669222]. [PubMed Central: PMC7451678].

17. Gordon H. Psychiatry, the law and death on the roads. Advances in Psychiatric Treatment. 2018;10(6):439-45. doi: 10.1192/apt.10.6.439.

18. Hussain M, Shi J, Batool Z. An investigation of the effects of motorcycle-riding experience on aberrant driving behaviors and road traffic accidents-A case study of Pakistan. Int J Crashworthiness. 2020:1-10. doi: 10.1080/13588265.2020.1774479.

19. Wells S, Mullin B, Norton R, Langley J, Connor J, Lay-Yee R, et al. Motorcycle rider conspicuity and crash related injury: case-control study. BMJ. 2004;328(7444):857. doi: 10.1136/bmj.37984.574757.EE. [PubMed: 14742349]. [PubMed Central: PMC387473].

20. Elliott MA, Baughan CJ, Sexton BF. Errors and violations in relation to motorcyclists' crash risk. Accid Anal Prev. 2007;39(3):491-9. doi: 10.1016/j.aap.2006.08.012. [PubMed: 17034747].

21. Barros AJ, Amaral RL, Oliveira MS, Lima SC, Goncalves EV. Traffic accidents resulting in injuries: Underreporting, characteristics, and case fatality rate. Cad Saude Publica. 2003;19(4):979-86. doi: 10.1590/s0102311x2003000400021. [PubMed: 12973564].

22. Rathinam C, Nair N, Gupta A, Joshi S, Bansal S. Self-reported motorcycle riding behaviour among school children in India. Accid Anal Prev. 2007;39(2):334-9. doi: 10.1016/j.aap.2006.09.002. [PubMed: 17049470].

23. Truong LT, Nguyen HTT, De Gruyter C. Correlations between mobile phone use and other risky behaviours while riding a motorcycle. Accid Anal Prev. 2018;118:125-30. doi: 10.1016/j.aap.2018.06.015. [PubMed: 29957439].

24. Akabri M, Sarikhani Y, Khatami K, Ardalan A, Safarpour H, Imanieh $\mathrm{MH}$, et al. The association between the score of adult attentiondeficit/hyperactivity traits and risky driving behaviors with alcohol intake and narcotics consumption among Iranian motorcyclists. Traffic Inj Prev. 2021;22(3):189-94. doi: 10.1080/15389588.2021.1877278. [PubMed: 33661079].

25. Taravatmanesh S, Hashemi-Nazari SS, Ghadirzadeh MR, Taravatmanesh L. Epidemiology of fatal traffic injuries in the Sistan and Baluchistan province in 2011. Safety Promot Inj Prev. 2015;3(3):161-8.

26. Khammarnia M, Amani Z, Hajmohammadi M, Ansari-Moghadam A, Eslahi M. A survey of iron supplementation consumption and its related factors in high school students in Southeast Iran, 2015. Malays J Med Sci. 2016;23(5):57-64. doi: 10.21315/mjms2016.23.5.8. [PubMed: 27904426]. [PubMed Central: PMC5101969]. 
27. Sakashita C, Senserrick T, Lo S, Boufous S, Rome LD, Ivers R. The motorcycle rider behavior questionnaire: Psychometric properties and application amongst novice riders in Australia. Transp Res F: Traffic Psychol Behav. 2014;22:126-39. doi: 10.1016/j.trf.2013.10.005.

28. Heydari ST, Sarikhani Y, Mani A, Mohammadi L, Vossoughi M, Lankarani KB. Factors associated with motorcyclist risky riding behaviors in southern Iran. J Inj Violence Res. 2019;11(2). doi: 10.5249/jivr.v11i2.1398.

29. Motevalian SA, Asadi-Lari M, Rahimi H, Eftekhar M. Validation of a persian version of motorcycle rider behavior questionnaire. Ann Adv Automot Med. 2011;55:91-8. [PubMed: 22105387]. [PubMed Central: PMC3256814].

30. Stephens AN, Brown J, de Rome L, Baldock MRJ, Fernandes R, Fitzharris $M$. The relationship between Motorcycle Rider Behaviour Questionnaire scores and crashes for riders in Australia. Accid Anal Prev. 2017;102:202-12. doi: 10.1016/j.aap.2017.03.007. [PubMed: 28324820].

31. Wang C, Xu C, Xia J, Qian Z. The effects of safety knowledge and psychological factors on self-reported risky driving behaviors including group violations for e-bike riders in China. Transp Res F: Traffic Psychol Behav. 2018;56:344-53. doi: 10.1016/j.trf.2018.05.004.
32. Boonchooduang N, Likhitweerawong N, Louthrenoo O. Prevalence of unprotected motorcycle riding and its association with other risk behaviors among adolescents in Chiang Mai, Thailand. Traffic Inj Prev. 2021;22(1):85-9. doi: 10.1080/15389588.2020.1844884. [PubMed: 33232180].

33. Haqverdi MQ, Seyedabrishami S, Groeger JA. Identifying psychological and socio-economic factors affecting motorcycle helmet use. Accid Anal Prev. 2015;85:102-10. doi: 10.1016/j.aap.2015.09.007. [PubMed: 26410724].

34. Nguyen-Phuoc DQ, De Gruyter C, Nguyen HA, Nguyen T, Ngoc Su D. Risky behaviours associated with traffic crashes among app-based motorcycle taxi drivers in Vietnam. Transp Res F: Traffic Psychol Behav. 2020;70:249-59. doi: 10.1016/j.trf.2020.03.010.

35. Pervez A, Lee J, Huang H, Papadimitriou E. Identifying factors contributing to the motorcycle crash severity in Pakistan. J Adv Transp. 2021;2021:1-10. doi: 10.1155/2021/6636130.

36. Pitaktong U, Manopaiboon C, Kilmarx PH, Jeeyapant S, Jenkins R, Tappero J, et al. Motorcycle helmet use and related risk behaviors among adolescents and young adults in Northern Thailand. Southeast Asian J Trop Med Public Health. 2004;35:232-41 
Table 1. Demographic Variables and Riding Behavior Score of Motorcycle Riders in the Southeast of Iran in 2019

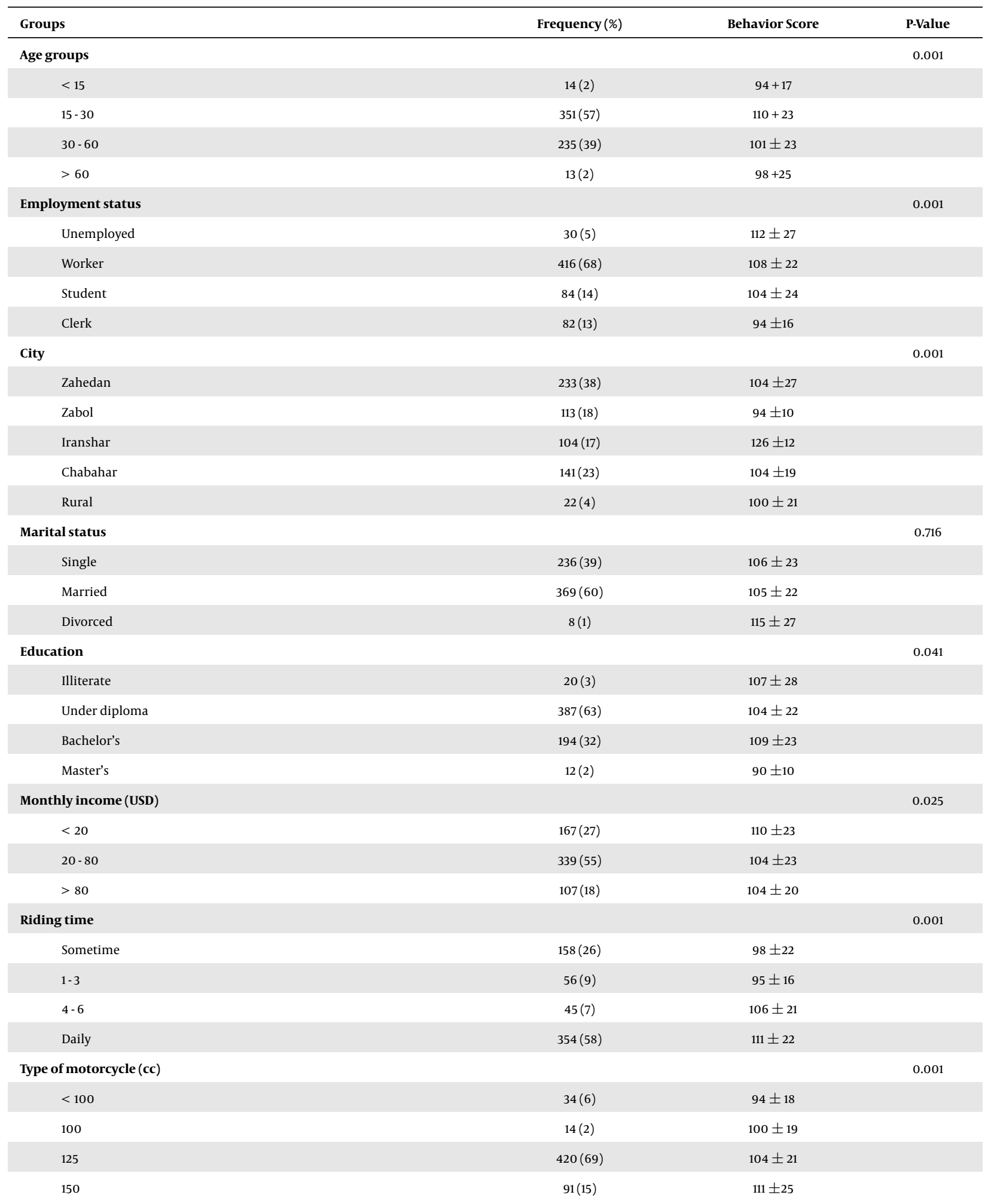




\begin{tabular}{|c|c|c|c|}
\hline 225 & $34(6)$ & $122 \pm 26$ & \\
\hline 250 & $9(1)$ & $119 \pm 13$ & \\
\hline$>250$ & $8(1)$ & $127 \pm 16$ & \\
\hline Motorcycle license & & & 0.001 \\
\hline Yes & $165(27)$ & $97 \pm 21$ & \\
\hline No & $448(73)$ & $109 \pm 22$ & \\
\hline Riding experience $(y)$ & & & 0.378 \\
\hline$<1$ & $36(6)$ & $111 \pm 25$ & \\
\hline $2-5$ & $145(24)$ & $104 \pm 23$ & \\
\hline$>6$ & $432(70)$ & $106 \pm 22$ & \\
\hline Age of starting to ride & & & 0.199 \\
\hline $10-18$ & $355(58)$ & $105 \pm 23$ & \\
\hline $19-29$ & $229(37)$ & $107 \pm 22$ & \\
\hline$>30$ & $29(5)$ & $101 \pm 20$ & \\
\hline Reason for using the motorcycle & & & 0.553 \\
\hline Work & $75(12)$ & $107 \pm 22$ & \\
\hline Travel to work & $353(57)$ & $106 \pm 22$ & \\
\hline Fun & $147(24)$ & $105 \pm 24$ & \\
\hline Others & $23(4)$ & $101 \pm 28$ & \\
\hline Travel to work and fun & $14(2)$ & $104 \pm 16$ & \\
\hline Received alerts in past year & & & 0.001 \\
\hline Yes & $183(30)$ & $111+23$ & \\
\hline No & $430(70)$ & $103+22$ & \\
\hline Crash experience & & & 0.003 \\
\hline Yes & $133(21)$ & $113 \pm 28$ & \\
\hline No & $480(79)$ & $104 \pm 20$ & \\
\hline Number of crashes in last year & & & 0.009 \\
\hline 0 & $478(78)$ & $104 \pm 20$ & \\
\hline $1-3$ & $126(21)$ & $113 \pm 29$ & \\
\hline$>4$ & $9(1)$ & $101 \pm 22$ & \\
\hline Use of helmet & & & 0.020 \\
\hline Always & $77(13)$ & $99 \pm 23$ & \\
\hline Often & $82(14)$ & $101 \pm 20$ & \\
\hline Sometime & $205(33)$ & $109 \pm 20$ & \\
\hline Rarely & $93(15)$ & $103 \pm 21$ & \\
\hline Never & $155(25)$ & $108 \pm 26$ & \\
\hline Use of safety equipment & & & 0.001 \\
\hline None & $303(49)$ & $103 \pm 22$ & \\
\hline Gloves & $160(26)$ & $104 \pm 23$ & \\
\hline Safety clothes & $10(2)$ & $96 \pm 14$ & \\
\hline Safety shoes & $54(9)$ & $114 \pm 20$ & \\
\hline Guard & $80(13)$ & $115 \pm 21$ & \\
\hline All equipment & $5(1)$ & $102 \pm 18$ & \\
\hline
\end{tabular}




\begin{tabular}{|c|c|c|c|}
\hline Use of mobile & & & 0.001 \\
\hline Always & $71(12)$ & $121 \pm 31$ & \\
\hline Often & $82(13)$ & $103 \pm 17$ & \\
\hline Sometime & $227(37)$ & $105 \pm 20$ & \\
\hline Rarely & $118(19)$ & $108 \pm 22$ & \\
\hline Never & $114(19)$ & $98 \pm 21$ & \\
\hline Speed exceeds & & & 0.001 \\
\hline Always & $65(11)$ & $117 \pm 31$ & \\
\hline Often & $104(17)$ & $107 \pm 20$ & \\
\hline Sometime & $212(35)$ & $109 \pm 20$ & \\
\hline Rarely & $132(21)$ & $104 \pm 21$ & \\
\hline Never & $97(16)$ & $93 \pm 20$ & \\
\hline Dangerous dramatic movements & & & 0.006 \\
\hline Always & $32(5)$ & $127 \pm 35$ & \\
\hline Often & $37(6)$ & $109 \pm 21$ & \\
\hline Sometime & $74(12)$ & $107 \pm 22$ & \\
\hline Rarely & $86(14)$ & $105 \pm 19$ & \\
\hline Never & $384(63)$ & $104 \pm 22$ & \\
\hline Riding in fatigue & & & 0.001 \\
\hline Always & $32(5)$ & $127 \pm 32$ & \\
\hline Often & $111(18)$ & $105 \pm 18$ & \\
\hline Sometime & $157(26)$ & $107 \pm 22$ & \\
\hline Rarely & $176(29)$ & $108 \pm 21$ & \\
\hline Never & $135(22)$ & $97 \pm 22$ & \\
\hline Talk to pillion passenger while driving & & & 0.001 \\
\hline Always & $141(23)$ & $117 \pm 14$ & \\
\hline Often & $90(15)$ & $110 \pm 26$ & \\
\hline Sometime & $217(35)$ & $106 \pm 19$ & \\
\hline Rarely & $115(19)$ & $108 \pm 23$ & \\
\hline Never & $49(8)$ & $95 \pm 23$ & \\
\hline Hands-free riding & & & 0.001 \\
\hline Always & $36(6)$ & $117 \pm 30$ & \\
\hline Often & $66(11)$ & $111 \pm 20$ & \\
\hline Sometime & $155(25)$ & $113 \pm 21$ & \\
\hline Rarely & $97(16)$ & $108 \pm 20$ & \\
\hline Never & $258(42)$ & $98 \pm 21$ & \\
\hline
\end{tabular}

